\title{
Dynamic of Innovation in Services for Consumers at the Bottom of the Pyramid
}

\author{
Gibson Meira Oliveira ${ }^{\Omega}$ \\ Universidade Federal da Paraíba \\ André Gustavo Carvalho Machado † \\ Universidade Federal da Paraíba
}

\section{ABSTRACT}

This paper aims to analyze the dynamic of innovation in services for consumers at the bottom of the pyramid (BoP). For this purpose, a framework composed of innovation dimensions, capabilities and infrastructure was developed. To assess the framework behavior in the business practice, a case study was carried out in a retail firm operating in Brazil's Northeast region whose target consumers are at the BoP. The results showed adherence of the proposed framework to the dynamics of innovation conducted by the studied firm. Considering the theoreticalacademic perspective, the framework helps explain the interaction between dimensions, capabilities, and elements of the market infrastructure. As for its practical relevance, it explains how service innovations occur and how to adapt them to the BoP market. In addition, as the structure of the proposed framework includes both external and internal elements, innovation is then considered from different perspectives.

Keywords: Bottom of the pyramid, Innovation in services, Retail.

\section{INTRODUCTION}

Innovation is related to the discovery, experimentation, development, imitation, adoption of new products, processes or organizational configurations and may arise from a new idea or market opportunity (DOSI, 1988; TIDD; BESSANT; PAVITT,2008). When analyzing the results of innovations undertaken by companies, particularly in sectors involving high technology, we may observe that innovation efforts tend to be oriented toward consumers belonging to the wealthier classes.

Some researchers (PRAHALAD; HART, 2002; PRAHALAD; HAMMOND, 2002; PRAHALAD, 2012), however, have drawn attention to the opportunity for gains by serving the mass population located at the base of the pyramid (BoP). The configuration of this segment, however, is complex, insofar as its population is conformed by an extreme social variety that is reflected in its levels of literacy, rural or urban location, income levels, cultural and religious diversity (PRAHALAD, 2010).

In addition, different research use different income limits to classify purchasing power (PRACEUS, 2014; HAMMOND et al., 2007), which makes it difficult to understand the size and composition of the BoP

Corresponding author:

${ }^{\Omega}$ Universidade Federal da Paraíba

E-mail: gibson.meira@gmail.com

† Universidade Federal da Paraíba

E-mail: agcmachado@gmail.com

Received: 08/04/2016. Revised: 08/29/2016 Accepted: 09/19/2016

Published Online: 08/01/2017. 
market. This lack of consensus seems to be due to some aspects: the definition of poverty varies according to the source adopted (e.g.: World Bank, Organization for Economic Co-operation and Development - OECD). Also, there are several methodologies both to establish the poverty line (SOARES, 2009) and to distribute social classes (Department for Strategic Affairs of the Federal Government - SAE, Criteria of Economic Classification Brazil of the Brazilian Association of Research Companies - ABEP, for example).

In this context, the pattern of poverty in countries with different degrees of development varies, as poverty lines tend to increase with development (PRITCHETT; KENNY, 2013). While the World Bank defines a poverty line (extreme poverty) in 1.90 USD per day (CRUZ, 2015), Pritchett and Kenny (2013) draw attention to the fact that in OECD countries this value is on average, of 12.5 USD per day. In this perspective, consumers classified in the lower strata of the social pyramid in certain developed countries would belong to the emerging middle class in developing countries (as is the case of Brazil).

From the divergences exposed, we consider in the present research, in line with Arnold and Valentin (2013), that the BoP is made up of people who consume less than 9.05 USD per day (including, therefore, extreme poverty, as defined by the World Bank and excluding the value stipulated by the OECD). In current values, this represents approximately 950 BRL per month, that is, more than one minimum salary. By using, in turn, the results of the Brazilian Demographic Census (IBGE, 2010), which uses nominal monthly household income per capita to describe the population distribution in bands defined by minimum salary numbers, The BoP would be inserted in the range that goes from "no income" to those who survive with an income equal to or less than two minimum salaries (per participant of the family residing in the same household).

It is possible to find in the literature examples of companies that have innovated to offer goods that cater to low income consumers (Hindustan Unilever, Nirma, GE Healthcare, Tata Motors, for example), however, there is a shortage of studies evidencing innovations in services with this purpose worldwide, and in particular in the Brazilian context. Despite this, the service sector in Brazil represents $69.4 \%$ of the Gross Domestic Product (GDP) (IBGE, 2013a) and it is in constant growth, which demonstrates not only its relevance to the economy but also the need for greater attention on the part of the companies regarding innovation in this sector.

Although several authors (BARRAS, 1986; GALLOUJ; WEINSTEIN, 1997; HERTOG, 2000; DE VRIES, 2006; KLEMENT, 2007; HERTOG; VAN DER AA; DE JONG, 2010) having proposed models to clarify how innovations occur in services, they do not contemplate the inherent specificities of meeting low income audiences, nor the infrastructure of the market of emerging countries. In this regard, the research problem is elaborated as follows: How does the dynamics of innovation in services occur in serving consumers in the bottom of the pyramid?

The central objective of this article, therefore, is to analyze the dynamics of service innovation in the service of consumers at the base of the pyramid. In order to achieve this purpose, a framework was initially developed, composed of dimensions associated with innovations in services together with elements that make up the infrastructure for the base of the pyramid. To evaluate the behavior of the proposed framework in business practice, we conducted a case study in a retail company operating in the Northeast region of Brazil and whose target segment are the consumers belonging to the BoP.

We understand that the research results have the potential to contribute to filling theoretical gaps associated with the way the process of innovations in services for the BoP occur, in particular the interaction between dimensions, capabilities and elements of market infrastructure for this purpose. From a practical point of view, the research results reinforce the understanding of the process of innovation in services, as well as explaining how it occurs and, lastly, they suggest how to adapt it to a differentiated market such as the BoP. 
BBR

14,6

611

After this introduction, the article is structured as follows: a review of the literature on service innovation models and commercial infrastructure at the base of the pyramid is initially presented. Then, in the said section, the developed framework is displayed and the dimensions and factors associated with it are discussed. In the third section we present the methodological procedures. In the fourth section, in light of the theoretical reference, the results of the analyzes are presented and discussed. Finally, some conclusions are drawn from the research undertaken.

\section{THEORETICAL FRAMEWORK}

In this section we discuss the main models of innovation in services arranged in the literature, and the framework developed for innovation in services for the base of the pyramid.

\subsection{SERVICE INNOVATION MODELS}

Service innovation, according to Barras (1986), occurs by means of the so-called "reverse product cycle", which is composed of three stages, following a dynamic that passes from the incremental phase, where improvements of quality and efficiency are made (which are put to test), to the point where new services are generated, characterizing the radical phase of the cycle. However, this model seems to have been designed to be applied to technologyoriented services, not appearing to fit contexts that shy away from technological possibilities (GALLOUJ, 1998).

Gallouj and Weinstein (1997), in turn, propose a General Model that dynamically encompasses four main elements: customer competence, service provider competencies, service provider technology and the final service. In the proposed model, the final characteristics of the products are results of the relation between two elements: technology and competences of the service provider. However, both are mutually influencing by means of intangible technical characteristics, codified and formalized competences, which are linked to the competencies of the service provider and are derived from various sources: initial training, continuing training, experience and, more generally, interaction.

Such a model represents a more general and significant situation of service provision, which requires the direct execution of knowledge and skills (codified and formalized), so that they can be used several times for the provision of similar or different services; as well as the mobilization of technical factors, which can be tangible (computer or telecommunications systems) or intangibles (modeling methods, legal assistance etc.).

The General Model, however, presents flaws in that it does not consider the technological capacities of the clients and the possibility of the existence of networks of different suppliers. To overcome these shortcomings, De Vries (2006) suggests a model that takes one more dimension to the model by Gallouj and Weinstein (1997), i.e., the customer's technology. The understanding is that there is a reciprocal role of co-production and alignment of technological specifications between the client and the service provider, with the former being the first responsible for innovating its own competences to dominate their own technology. In addition, the customer relationship does not have to be limited to an interaction with a provider, and may also occur with a network of service providers.

Klement (2007), in turn, developed a service innovation model that considers the changes made in the final characteristics of the services, which may be the result of the interaction between: customer's competences, competences and technology of the intermediary; competence and technology of the service provider. However, despite the contribution of the model to include the role of intermediaries, it does not consider client technology itself, as proposed by De Vries (2006). 
Innovation in services, however, is something that is not restricted only to changes in the final characteristics of services. Sometimes it is combined with new distribution formats, customer interaction, quality assurance and quality control (HERTOG, 2000). In this regard, this author proposes a model composed of the interaction between four dimensions (4D): new concept of service; new customer interface; new delivery system; and technological options.

The dimension of the new service concept basically deals with how the innovation in service is presented and how it is conceptualized when applied to a particular market. The second dimension, termed as the new customer interface, addresses the external relationship in the innovation process in service. We understand that there are services that are focused on the specific and individual needs of the clients, requiring their participatory action. Such cooperation may therefore provide for the extension of the innovative potential of the company.

The new service delivery system, third dimension, is directed to an internal arrangement of the organization that enables workers to perform their functions properly, so that innovative services can be developed and offered. It is possible that innovation occurs in services without necessarily involving technology, however, there is a vast relationship between "technology" and "service innovation". This is the key point of the fourth dimension, since the available technology is seen as a facilitator, which means that there is a differentiation in the technological awareness available in the company, directly impacting on the way in which the service being offered to the customer will be handled.

More recently, Hertog, Van der AA and De Jong (2010) reviewed the 4D model with the addition of two more dimensions and reviewing the previous ones suggested, transforming it into the 6D Model, composed of the following dimensions: new concept of service; interaction with the new customer; new business partners; new revenue template; new delivery systems: people, organizations and culture; new delivery system: technology.

In the 6D Model, the importance of the development of dynamic capabilities for innovation in services is also unprecedented. These are: signaling user needs and technological options; conceptualizing; the ability to (dis)aggregate; coproduce and organize; scale and extension; and, finally, to learn and adapt (HERTOG; VAN DER AA; DE JONG, 2010). Therefore, the model performs an alignment with regard to the dimensions related to the innovation process in services and the dynamic capacities involved, taking into account certain aspects involving not only the service provider, but also the customer.

The models presented seek to explain how the dynamics of innovation in services occur in a broad way. Meeting the needs of the BoP, however, is not the same as serving the better or more efficient markets already in existence. In addition, it is necessary to develop a tailored business infrastructure to deal with the challenges, at least four key elements: creating buying power, shaping aspirations, improving access and tailoring local solutions (PRAHALAD; HART, 2002).

With regard to the creation buying power, we should remember that, in the case of a lowincome market, the vast majority of the population has no buying power or is involved in informal jobs (PRAHALAD; HART, 2002; PRAHALAD; HAMMOND, 2002; LONDON; HART, 2004), making it difficult to provide credit. However, while loans are made available to the population, economic leverage is promoted, which consequently, will allow the generation of income.

In considering that BoP is associated with emerging markets, there are characteristics that need to be observed with respect to the distribution systems, since these, as well as the communication systems, are relatively precarious compared to the more developed markets (ARNOLD; QUELCH, 1998; PRAHALAD; HART, 2002; CHIKWECHE; FLETCHER, 2012), it is often necessary to develop such aspects in order to make better use of the market. 
BBR

14,6

613

The target public of companies that operate in the BoP has limited capital, thus, normally, they make small purchases due to lack of storage space, leading to a greater likelihood of substitution between the "brands" of products offered on the market (PRAHALAD; HART, 2002). More targeted products, made exclusively and in simple packaging, can become a differential.

In this context, we note the absence of models that could explain the innovation process in services directed to the BoP market, considering their respective specificities, in particular with regard to commercial infrastructure. Therefore, in order to contribute in filling the gap, we propose a framework that represents the dynamics of service innovation to the base of the pyramid.

\subsection{FRAMEWORK FOR SERVICE INNOVATION FOR THE BASE OF THE PYRAMID}

The models presented by the authors (BARRAS, 1986; GALLOUJ; WEINSTEIN, 1997; HERTOG, 2000; DE VRIES, 2006; KLEMENT, 2007; HERTOG; VAN DER AA; DE JONG, 2010) address service innovation in generic situations, and at times, they present restrictions to certain contexts, often not taking into account the characteristics of the market itself.

Considering that none of the models presented is in line with the reality and characteristics intrinsic to the market at the BoP, Figure 1, below, presents a proposition of a framework that can better explain how the dynamics of the innovation process occurs in this type of market, taking into account factors such as the strategies and the commercial infrastructure in BoP.

The framework presents four dimensions associated to the innovation process in services, and they are interconnected by certain selected factors. The dimensions also have connection with four other characteristics that represent the infrastructure of the BoP market, which directly impact the dimensions highlighted. It is based on the 4D model (HERTOG, 2000) and BoP's market infrastructure (PRAHALAD; HART, 2002). We made some modifications, with a view to adapting it to what is expected of an organization when developing services directed to a layer of the population with differentiated characteristics.

Although Hertog, Van der AA and De Jong(2010) suggest a model of service innovation where certain dynamic capabilities of the organization are contemplated, our interest in this research is focused on the relations between the innovations and the elements of the infrastructure that support the commercial success of them in the context of the base of the pyramid. Thus, since the analysis of the behavior of the dynamic capacities is not part of the objectives of the present study, the 4D model (HERTOG, 2000) seems to be most suitable for the purposes of this research.

In the "4D" model" (HERTOG, 2000), the first dimension is defined as "New concept of service", in which the acceptance of innovation in the service is related to the perception of the market and the customers. Therefore, market issues directly influence this dimension, and the concept of new service will depend on the market in which it is being offered. Considering that the infrastructure of the BoP market has different characteristics from the other, the original nomenclature of this dimension has been replaced by the term "Market Interface" (first dimension), aiming at a better alignment with what we intend to study, that is, innovation in services for the BoP.

Addressing a differentiated market is something that needs a deeper understanding of certain existing characteristics, such as the purchasing potential of likely customers, employability, access to credit, pricing policies, suppliers, competitors, and so many other elements that make up the market as a whole. Thus, the first dimension of the proposed framework is termed as Market Interface. 


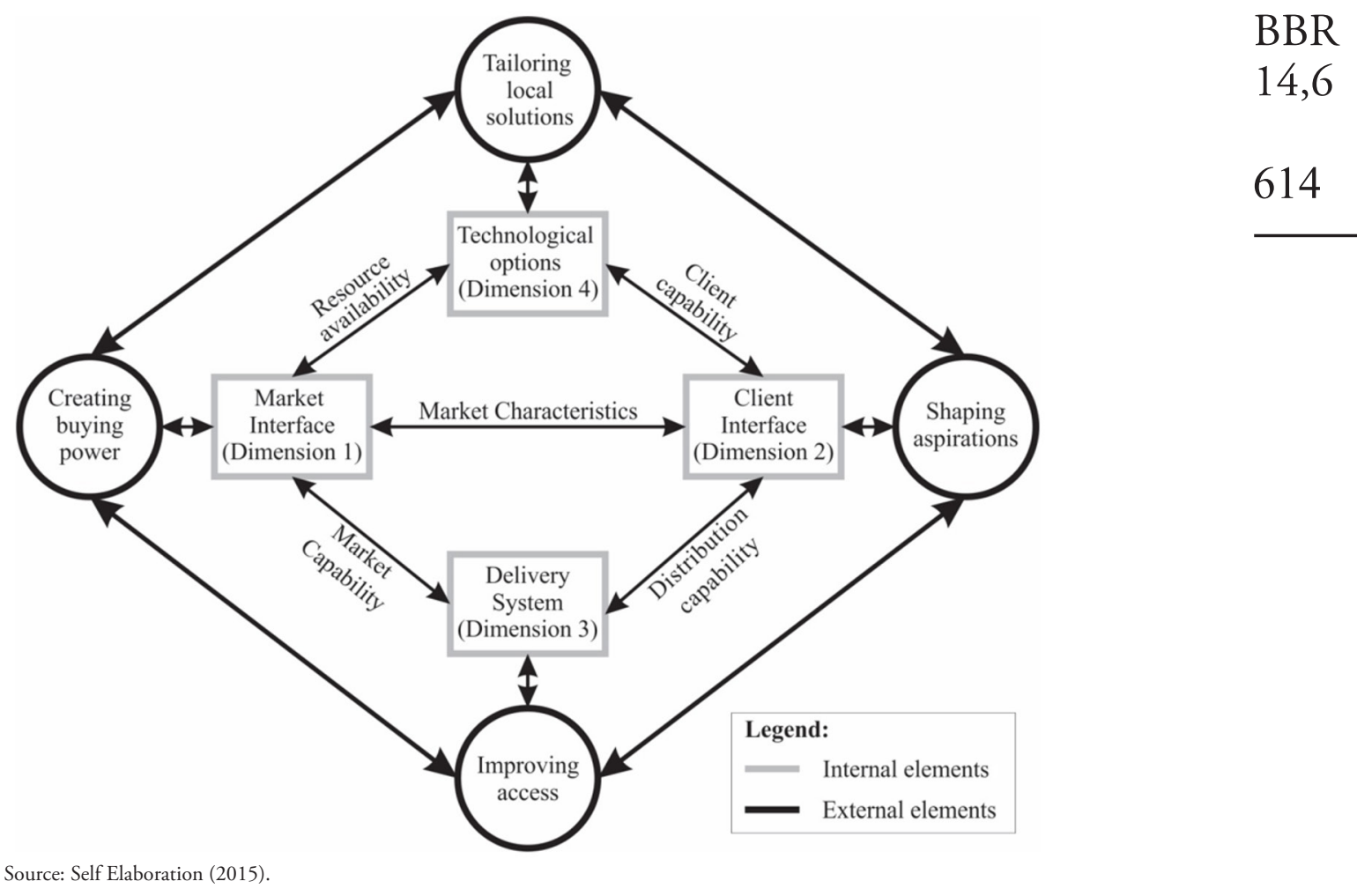

Figure 1. Framework for service innovation for the base of the pyramid.

The Customer Interface, second dimension, encompasses elements that are peculiar to the target audience, involving everything from the financial situation to the most complex ones, such as those related to the level of education and schooling of the potential consumer. This dimension has a more specific approach than the previous one, turning its attentions to the more punctual properties of the client and the way in which innovation will impact it.

The way the service will be offered or made available, as well as the access to it, represents the third dimension, denominated Delivery System. In this dimension, we observe the innovations carried out by the company that involve improvements in the way the result of the service will be delivered to the final consumer, also contemplating the commercialization or execution of the service.

The fourth dimension involves Technology Options. Innovations do not always involve technology, however, technological tools can be used to improve aspects such as quality, cost and others. In the absence of a particular resource, companies can seek it through the development of new technologies, solving the problems caused by the absence or seeking the development of technologically leaner products.

Dimensions, in their individuality, represent the specific characteristics of the market, customer, delivery system or available technologies, but in practice, these elements are not isolated, and there is a relationship that occurs through common factors between two or more dimensions, which are the capacities and availability.

The capacity factor is related to three dimensions (market, customer and delivery system), establishing a connection between them. The market capacity, which connects the first dimension (Market Interface) to the third dimension (Delivery System), in the proposed model, replaces the organizational capacity of the 4D model by Hertog (2000), by the fact that both dimensions are directly associated with the skills and structure of the market.

The affinity with available service technology and usability potential is the ability of the customer. This factor relates the customer interface to the technological options. Therefore, 
BBR

14,6

615

it is essential that there is an affinity or knowledge of the available technology so that it can used.

The market, besides the consumer, also presents itself as supplier of intangible elements, such as information, professional qualification or knowledge, inputs that can become a barrier to the organization's innovation process. The fourth dimension relates to the first dimension through the availability of resources (raw materials, technology, labor, information and other) which are of easy access in the market.

Creating buying power, shaping aspirations, improving access and tailoring local solutions: the four elements of the commercial infrastructure at the base of the pyramid are interlinked, since the innovation in one of the elements ends up influencing the other (PRAHALAD; HART, 2002).

To meet the needs of a market at the BoP, according to the Prahalad and Hart (2002), it is necessary to adapt to the reduced buying power of the population, for which the provision of credit or the generation of employment enable the access to capital in some way, factors that have an impact on dimensions one. To model the aspirations, that is, preparing the consumer for a given service, through a process of education, instruction and/or demonstration, is something that has a direct influence on the second dimension, since the customer must be prepared for the service, just as he/she must know what is being offered.

Among other characteristics of this market is the difficulty of access to the customer due to the natural remoteness of shopping centers, since, normally, such a public concentrates its housing units in peripheral areas, thus requiring better planning in terms of accessibility to the service. Thus, in a market at the BoP, a system of distribution of goods or services is needed, as well as better communication with customers, factors that are directly related to dimension three.

Finally, because the framework is aligned with a given context, it is understood that it is not suitable for the innovation process aimed at all market types, which makes it impossible to apply it to a reality which differs from that of the BoP. In addition, the role of the company is seen as a passive element in the aspects studied, not being directly constituted as an agent transforming the elements of the market infrastructure. Empirical studies, therefore, should be developed to evaluate the adherence of the framework to practice. The test of the model will allow its adjustment, if inconsistencies are found that might undermine its purpose.

\section{METHODOLOGICAL PROCEDURES}

In order to evaluate the framework developed to understand the dynamics related to innovation in the services provided by companies that deal with the public of the BoP, we used the case study research strategy (EISENHARDT, 1989; CHETTY, 1996) in a retail company. The focus of attention on the low income public, the fact that their units are located in the Northeast region of Brazil, innovations in services undertaken (installment plans, customer service, delivery system etc.) and accessibility were the main criteria used to select the case. The selected company has 50 years of existence, more than 40 stores distributed in several states of the Northeast region of the country, and employs approximately 2000 people. The choice of a company located in the Northeast region is due to the fact that this region has the lowest Gross Domestic Product (GDP) per capita in Brazil (IBGE, 2013b).

Certain characteristics aligned to the BoP market, inherent to the case, and likely to be evaluated by the proposed framework, also contributed to the selection of the company, such as: the form of service; the system of delivery of goods purchased by customers; the adoption of technology to support the execution of day-to-day tasks; and the strategies adopted to creating buying power, tailoring local solutions and shaping aspirations. 
The data were collected between August and November 2014 and September 2016, through semi-structured interviews, direct observation and analysis of documents, in order to allow for the triangulation of the data. We interviewed in all, six professionals, five administrative assistants and a store manager. For both the interviews and the observations, we adopted scripts specifically constructed for the purposes of the research.

The interview script is composed of 12 questions that include a set of aspects inherent to the dynamics of the innovations in services and the necessary infrastructure for the provision of services to the BoP, such as: the role of technology and customer influence, resources and capabilities and skills, distribution channels, access to services, programs or policies for employability, and income generation for low-income people.

The observation script included elements associated with physical aspects (objects, resources, available technologies, management in sight, physical arrangement), with customers (number of customers waiting and whose needs are being met, service delivery environment) and with access to the public (location of facilities, opening hours, correlated services, facilitators). The analyzed documents mainly involved records of activities carried out.

We recorded the interviews in digital mode and later transcribed by professionals paid for this purpose. Subsequently, we elaborated a document incorporating the interviewees' reports, the results of the observations and the analysis of the documents. The next step was to send this document to the respective interviewees with the intention of validating it. At that point, we suggested to the professionals of the researched company to feel free to include or suppress information so that the final document reflects the reality of the innovation process in the services provided to clients.

After feedback from the interviewees, we categorized and grouped the data, based on aligned dimensions of emerging events, such as: innovations from the perspective of the company and the sector, aspects internal to the company and market structure. Then, we confronted the data with the literature in order to subsidize conclusions on the framework initially proposed.

\section{ANALYSIS AND DISCUSSION OF RESULTS}

The objective of the framework presented in section 2 is to know the dynamics adopted by the companies in the process of service innovation for the BoP and, therefore, deepen the knowledge and verify which market aspects are involved in the procedures adopted by the Company.

The proposed framework is composed of four dimensions that are related to aspects internal to the organization. They are: market interface, customer interface, delivery system and technology options, which are connected by factors that are related to resource availability and customer capabilities, market capacity and distribution capacity. In an external context, there are four elements that make up the market infrastructure, which are: creating buying power, tailoring local solutions, shaping aspirations and improving access.

The market interface is the first dimension of the framework, which brought together issues that are peculiar to the market in which the Company is inserted, such as the target audience's purchasing potential, pricing policy, forms of payment, direct and indirect competitors and other components of such a structure.

The Company operates in the retail trade of domestic items, with stores distributed in four states in the Northeast region of the country, covering a market composed of, practically, all social classes. However, attention and efforts are focused on the audience that compose the $\mathrm{BoP}$, as one of the interviewees points out: 
BBR

14,6

617

The focus of the company is the customer from classes C and D. Our prices, promotions and advertisements are directed to these consumers. We try to be as instructive and informal as possible in communications and service because we know of the shortcomings of our public, the majority formed by simple people who live in small towns in the countryside and in rural areas. Due to this characteristic, we stand out in the logistics services, because we deliver our products in places that freight service providers deny, because they involve ranches, farms and places of difficult access. For this, we have our own fleet of vehicles and own assemblers. Our stores are purposely not sophisticated nor do we prefer being in shopping centers (only two stores are located in popular malls). We arrange the layout of the store as if it were the home of our customers, since among our products we also sell furniture. This makes them feel more at home.

As observed by direct observation in comparison with some competitors in the market, lower prices for certain products, installment purchases (up to 12 installments without interest) in all credit card flags and installment plans are strategies that have been developed to make the goods commercialized by the Company accessible to the low income public, in line with the availability characteristic proposed by Anderson and Markides (2007) and Prahalad (2012).

Unlike in stores located in large urban centers, the Company provides installment plans in smaller cities and those far from capitals (less than $20 \%$ of stores are located in capitals). These cities are mostly composed of a population whose income is derived from rural activities, small local businesses, and informal jobs. This demonstrates the attention to policies of access to credit for an economically disadvantaged public, who needs payment facilities so that they can purchase. In this regard, one of the professionals interviewed explains:

We deal with many freelancers, people who do not have a paycheck, who do not have a credit card. Thus, we also adopt payment cards and conduct a differentiated service, using a language the client can understand, seeking to understand their needs to provide credit. In smaller countryside cities, what works is trust. The store manager knows people by name because they live near them and, unlike what they might assume, the delinquency rates are low, because added to the trust and the proximity, the humbler people understand that the their name (and their word) is the most precious possession they have.

Throughout its more than 50 years of operation, the Company has sought to serve the consumer public with quality products at low prices. For this, in addition to constant negotiations with suppliers, the Company decided to invest in factories to provide own brand products. It is the case of furniture and upholstery that are manufactured internally and contribute to the reduction of transaction costs. Thus, by what is said by Prahalad and Hart (2002), Prahalad and Hammond (2002) Prahalad (2010) and Prahalad (2012), it is noticeable that the Company is aligned with the BoP market.

In the second dimension of the framework we analyze specific situations that involve clients, such as financial, educational and cultural factors, highlighted by Prahalad (2010) and Prahalad (2012), and how these characteristics influence the process of innovation. Thus, we analyze elements that describe the client interface.

The Company appeared in a city located in the country side of a northeastern state, and as soon as it was founded, it commercialized goods of the most diverse types and prices, with the customers being responsible for the increase in the variety of items available, since, while searching for a particular good in the shops, and not finding it, its owner immediately sought a way to provide it in future occasions. 
In so far as any consumer dissatisfaction in relation to service delivery was perceived, changes in the format of service were arranged or even the people responsible for sales or store management, aiming to improve the process and ensure the satisfaction of its target audience. Therefore, the influence of the client in the management process is perceived. Considering the above, the client represents a dimension present in the proposed framework, being, through its characteristics, an influential element in the Company's innovation processes.

The delivery system represents the third dimension of the framework under study, gathering characteristics related to the delivery of the service (in this case, the fulfillment of the process by delivering the acquired good) and the way the Company has done to provide customer access.

The Company's stores are distributed in several cities in the Northeast region of Brazil, including those with a lower number of inhabitants. In places where its stores are not present, publicity campaigns are carried out, using pamphlets and cars equipped with speakers to announce the nearest store. In addition, the Company has Distribution Centers (DC), which facilitate the delivery of the goods in reduced time. Upon completion of the sale, a delivery order is issued electronically to the DC closest to the address provided by the customer.

There is an effort to get the goods delivered to customers, regardless of the level of difficulty for access to the locality, whether in the urban or rural perimeter. As informed by one of the interviewees: "even if the truck does get through, deliveries are performed by bicycle or the product is transported over the head; The important thing is that the customer receives the product purchased in their residence".

The last dimension, the technological options, represents the availability of technological resources available to the Company, also involving qualified manpower and technical knowledge from internal and external customers.

The company has adopted to control procedures and processes, the information technology system (IT) of the company TOTVS, termed as Phroteus. To install it, it was necessary to carry out a process of customization of the system so that it suited the reality of the Company. Professionals from different areas influenced the entire customization process to allow better alignment to the daily needs of each sector.

Often, due to competitiveness, innovation, according to Vrakking (1990), is a way of strengthening the player in the market; therefore, it is necessary for the company to build its own solutions, together with its employees, in view of the fact that in the market, problemsolving techniques or competitiveness strategies are usually protected by competition.

However, certain innovations used and applied by the company were available in the international market, for example, the QR Code. The Company was one of the first to adopt such a system for issuing the tax coupon, greatly facilitating customer access to electronic invoice, thus allowing greater integration with the Federal Revenue Service.

QR Code technology and IT systems were possible innovations for the Company due to the reach and availability of technologies in the market, which enabled the implementation and use of resources that are aligned with their needs. Thus, it can be considered that the fourth dimension of the model under study is present in this case.

The four dimensions are connected by elements that represent the availabilities and capacities of several questions addressed in the model. Knowing how the Company treats these factors makes it possible to understand to what extent the market influences the daily life of the company. In this regard, the availability of resources is a factor that connects the dimensions one and four of the framework, representing the resources that are available to the Company.

The Company, before installing a store in a certain city, previously performs a process of selection and recruitment of labor, employing people from the locality. For management and supervision positions, a training is provided that will allow a better qualification of 
BBR

14,6

619

the professional. Regarding the market capacity, considering the demand created by the governmental policies of social inclusion that have been implemented in Brazil in the last decade, and the Company's long time of operation, with several stores in different cities, it is possible to conclude that the market has been able to absorb what is offered by the company.

Just as the customer has influenced the processes of innovation and expansion of the variety of goods available in stores, The Company has sought to take advantage of not only the technological resources currently available, but also the ability of customers to use them. The technology has enabled the customer to access the electronic invoice through the use of their smartphone as a two-dimensional bar code scanner, so the customer can save or print the invoice of the product purchased in the store. Thus, it is possible to perceive that there is a reutilization of the capacities of the clients.

The distribution of the goods sold in their stores is carried out with own trucks. Deliveries are carried out in almost any locality, whether or not it is accessible to the vehicle, as already mentioned. Thus, the distribution capacity of the store is something that influences the dimensions two and three, since the customer, as a demander of the service, makes the company responsible for the delivery of the goods. It is possible, therefore, to perceive that there is influence of the availability of resources, of market capacities, the distribution capacity and the capacity of the customers on the innovation processes adopted by the Company, in line with the elements proposed in the framework.

In addition, the framework has four elements that make up aspects external to the organization. They represent the market infrastructure proposed by Prahalad and Hart (2002), which includes: creating buying power, tailoring local solutions, improving access and shaping aspirations.

The first element, creating buying power, is achieved through the employability generated from the opening of stores, considering that people from that particular location are hired to provide services to the company, generating income so that they become potential buyers. Another solution found to generate buying power is to offer clients the choice to pay in installments, which is widely used in smaller cities in which the Company operates.

A relevant aspect and highlighted by Prahalad and Hammond (2002) and Anderson and Makides (2007) is in relation to access. In the Company, this is made possible, mainly, through the distribution of stores in several cities, be they located in the capitals or within each state, and facilitated by means of their own delivery system. As pointed out by Arnold and Quelch (1998), Prahalad and Hart (2002) ad Chikweche and Fletcher (2012), the communication between the company and the customer corresponds to a fundamental aspect with regard to access. From this perspective, considering that the Company's policy is to hire local labor, communication between sellers and consumers is facilitated, especially in shops located in small cities, as both are part of the same community, not rarely do they know each other and share the same expectations.

Tailoring local solutions occur when different services are available to meet the particular requirements of customers. The payment method is one of the characteristics that is conditioned to the location, for example: in large urban centers there is no available credit modality; the use of technology that allows access to the electronic invoice is a solution that is also aligned with the profile of the buyer. Another relevant aspect is the delivery format, which often has to be adapted to the conditions of the customer's residence location, requiring effort and creativity on the part of the deliverers.

Shaping consumer aspirations, in turn, is related to what the Company has undertaken to gain access to its target audience. The Federal Government, together with the Social Program "Minha casa, Minha vida" (popular housing program, which facilitates the acquisition of houses for low-income people), released a facilitated the installment plan called "Minha casa melhor", whose purpose is also to finance to the low-income public the 
purchase of household items. In order to educate the population to use the Program properly "Minha casa melhor" and enjoying the potential for sales from consumption, managers of the Company's stores have visited homes in needy communities to teach how the Program works and to help people gain access to credit.

In addition, marketing campaigns are carried out to inform the consumer where the nearest store is located. Giving out flyers, advertising with cars equipped with speakers, and media through television and radio stations are also carried out, where information related to the diversity of products available, as well as facilities for payment are disclosed.

We note, therefore, that there is convergence of the proposed framework to the reality presented by the Company, there being an alignment between the propositions by Prahalad and Hart (2002) and Hertog (2000) regarding the market infrastructure for the pyramid base and the service innovation model, respectively.

\section{CONCLUSIONS}

Innovation, as initially understood by Schumpeter (1961), is an internal process of creative destruction, in which products, gradually, cease to exist, giving space to others that meet new requirements or are more efficient than previously available ones. However, in addition to this inside-out perspective, developing and aligning innovations to the evident and latent needs of the market also present themselves as fundamental to competitive purposes. Thus, efforts have been made to generate disruptions that enable companies to serve new markets and new customers.

From the perspective of services, despite its expressive expansion and representativeness in the world economy, studies associated with innovation in the sector are marginal when compared to published results on the development of tangible products. With the exception of studies by Knight (1967), in the 1960s, the understanding of innovations was for many years primarily focused on physical goods. However, in the second half of the 1980s, Barras (1986) starts to study services in a differentiated way, appearing, several models from then on, that try to explain how innovation occurs in services.

The models presented by the authors, over time, treat service innovation in generic situations, presenting restrictions to certain contexts, not often taking into account the characteristics of certain specific markets. In this context, the proposed framework, when compared to the models developed by the authors in the last decades, represents an evolution in the study of the innovation process directed to a certain target audience. the advance is occurring at a time when certain gaps are being filled, such as the perception of market-related characteristics, customer and technology, also considering the specifics of the market regarding the intrinsic limitations at the base of the pyramid. The dimensions that are contained in the model, in turn, contemplate the various factors in the innovation process. In addition, once both external and internal elements are considered, innovation will be considered from different points of view.

When evaluating the behavior of the different characteristics of the framework in business practice, we may observe strong adherence to the observed reality. Through the analysis of internal aspects, we perceived that credit is one of the main strategies adopted by the Company analyzed in the market interface dimension. Although this result is not surprising - Prahalad (2010) had already found that, in the early years of the 2000s, this same strategy was already being adopted by the largest retail company in Brazil: Casas Bahia -, there have been no significant advances in the interaction with BoP consumers since its publication.

The interaction with the client, represented in the second dimension of the framework, has been fundamental so that the Company, since its foundation, would act not singly to adapt its offers and operations to the changing needs of the market. The adoption of strategically located Distribution Centers and a distribution logistics that includes a fleet of trucks and 
BBR

14,6

621

own personnel have favored the delivery of goods in locations farthest from urban centers, characterizing the efforts undertaken in the third dimension. IT investments have, in turn, enabled the management of operations and were the fourth dimension analyzed.

The four theoretically suggested infrastructural elements were also verified in practice. Creation buying power may be seen, either by the initiative of the Company (job opportunities to the local community, installment plans), or by Government Programs explored by the Company. Access is guaranteed by the geographical distribution of the stores and by the delivery system. Marketing campaigns and efforts of store managers to teach potential customers to sign up for and properly use installment plans offered by the Government to purchase household items are the main actions aligned to the aspiration modeling contemplated in the third element of the infrastructure for the BoP. Differentiated delivery services and different payment terms (according to geographical location) are examples of locally adapted solutions.

While models, innovations and business strategies to market goods and services at affordable prices can contribute to improving the quality of life of the low-income population, the eradication of poverty, different from what Prahalad (2010) suggests, and aligned with the reflections by Landrum (2007), do not contemplate only the inclusion of the poorest in the consumer market. More than access to products, as is pointed out by Karnani (2007), private enterprises should contribute to qualify people in need of skills and competences in line with market requirements, so that they can not only have more job opportunities but also become competitive entrepreneurs. This last understanding goes against the logic proclaimed by different authors (PRAHALAD; HART, 2002; PRAHALAD; HAMMOND, 2002; LONDON; HART, 2004), to the extent that it perceives the poor not as a passive consumer, but as a potential producer, which, if endowed with managerial capacity, adequate resources and inclusive public policies, can not only increase their income but also generate new jobs.

In addition, to attribute poverty reduction solely to consumption decisions by the poor, as a central proposition of research focused on the BoP, seems to be a misunderstanding. The fact that less well-off people have precarious education, lack of access to information and other cultural, social and economic deprivations Karnani (2009), that their financial choices may be more influenced by marketing approaches that meet corporate business objectives than by conscious and responsible behavior that has its own benefits.

This is also the understanding by Arnold and Valentin (2013), when drawing attention to a necessary reflection on the instrumental social responsibility versus ethics of companies that deal with the BoP segment. For these authors, while the instrumental perspective asserts that exploiting the vulnerability of the poor and not considering their basic human rights are options for managers as long as the sale of the products leads to positive financial returns, making business decisions based on ethical elements (key characteristics of corporate social responsibility) considers profit together with values associated with the reduction of inequalities and actions that lead to the awareness of people about their rights to overcome social dependence.

Considering that the framework is applied in only one company in the retail sector, we suggest, as an agenda for future studies, the conduction of survey-type research, in a wide universe of companies, whose main interest is the meeting the needs of consumers at the $\mathrm{BoP}$, in order to validate the proposed framework. In addition, despite the potential for gains from innovations targeting the low-income public, research should be undertaken to better ascertain and measure the respective social impacts. 


\section{REFERENCES}

ANDERSON, J.; MARKIDES, C. Strategic innovation at the base of the pyramid. MIT Sloan Management

ARNOLD, D. J.; QUELCH, J. A. New strategies in emerging markets. Sloan Management Review, v.40, n. 1, p. 7-20, 1998.

ARNOLD; VALENTIN, A. Corporate social responsibility at the base of the pyramid. Journal of Business Research, v. 66, n. 10, p. 1904-1914, 2013.

BARRAS, R. Towards a theory of innovation in services. Research Policy, v. 15, p. 161-73, 1986.

CHETTY, S. The case study method for research in small-and medium-sized firms. International Small Business Journal, v.15, n. 1, p. 73 - 85, 1996.

CHIKWECHE, T.; FLETCHER, R. Revisiting the marketing mix at the bottom of pyramid (BoP): from theoretical considerations to practical realities. Journal of Consumer Marketing, v. 29, n. 7, p. 507-520, 2012.

CRUZ, M.; FOSTER, J.; QUILLIN, B.; SCHELLEKENS, P. Ending Extreme Poverty and Sharing Prosperity: Progress and Policies. Washington D. C.: World Bank, 2015.

DE VRIES, E. J. Innovation in services in networks of organizations and in the distribution of services. Research Policy, v.35, n. 7, p. 1037-1051, 2006.

DOSI, G. Sources, procedures, and microeconomic effects of innovation. Journal of Economic Literature, v. 26, n. 3, p. 1120-1171, 1988.

EISENHARDT, K. M. Building theories from case study research. Academy of Management Review, v. 14, n. 4 , p. 532-550, 1989.

GALLOUJ, F.; WEINSTEIN, O. Innovation in services. Research Policy, v. 26, p. 537-556, 1997.

HAMMOND, A. L.; KRAMER, W. J.; KATZ, R. S.; TRAN, J. T.; WALKER, C. The next 4 billion: Market size and business strategy at the base of the pyramid. Washington, D.C.: World Resources Institute and International Finance Corporation, 2007.

HERTOG, P. D. Knowledge-intensive business services as co-producers of innovation. International Journal of Innovation Management, v. 4, n. 4, p. 491-528, 2000.

HERTOG, P. D.; VAN DER AA, W.; DE JONG, M. W. Capabilities for managing service innovation: towards a conceptual framework. JournalofService Management,v. 21, n. 4, p. 490-514, 2010.

IBGE.Censo demográfico e contagem da população: domicílios particulares permanentes, por classes de rendimento nominal mensal domiciliar per capita.2010. Retrieved from http://sidra.ibge.gov.br/bda/tabela/ protabl2.asp? $\mathrm{c}=3261 \& \mathrm{z}=\mathrm{cd} \& \mathrm{o}=4 \& \mathrm{i}=\mathrm{P}$.

. Contas nacionais trimestrais: indicadores de volume e valores correntes, outubro / dezembro 2013.

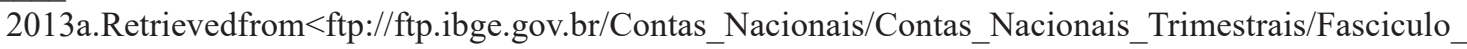
Indicadores_IBGE/pib-vol-val_201304caderno.pdf $>$.

. Contas regionais do Brasil 2010-2013.2013b. Retrieved from http://saladeimprensa.ibge.gov.br/noti cias? view $=$ noticia\&id $=1$ \&busca $=1 \&$ idnoticia $=3038$.

KARNANI, A. The mirage of marketing to the bottom of the pyramid: how the private sector can help alleviate poverty. California Management Review, v. 49, n. 4, p. 90-111, 2007.

. The Bottom of the Pyramid Strategy for Reducing Poverty: A Failed Promise. DESA working paper n. 80, New York: United Nations Department of Economic and Social Affairs, 2009.

KLEMENT, C. F. F. Inovação em serviços: estudo de casos em uma organização da indústria hoteleira brasileira. 2007. Tese (Doutorado em Administração) - Faculdade de Economia, Administração e Contabilidade, Universidade de São Paulo, São Paulo, 2007. Disponível em: <http://www.teses.usp.br/ teses/disponiveis/12/12139/tde-28092007-181505/>. Acessoem: 17 mai. 2016.

KNIGHT, K. E. A descriptive model of the infra-firm innovation process. The Journal of Business, v. 40,n. 4, p. 478-496, 1967.

LANDRUM, N. Advancing the 'base' of the pyramid debate.Strategic Management Review, v. 1, n. 1, p. 1-12, 2007.

LONDON, T.; HART, S. L. Reinventing strategies for emerging markets: beyond the transnational model. Journal of International Business Studies, v. 35, n. 5, p. 350-370, 2004.

PRACEUS, S. Consumer Innovation at the Base of the Pyramid: Emerging Patterns of User Innovation in a Resource-Scarce Setting. Hamburg: Springer Gabler, 2013.

PRAHALAD, C. K. A riqueza na base da pirâmide: como erradicar a pobreza com o lucro. Porto Alegre: Bookman, 2010. 
BBR

14,6

623

.Bottom of the pyramid as a source of breakthrough innovations. Journal of Production and Innovation Management, v. 29, n. 1, p. 6-12, 2012.

PRAHALAD, C. K.; HAMMOND, A. Serving the world's poor, profitably. Harvard Business Review, p. 4-11, Set. 2002.

PRAHALAD, C. K.; HART, S. L. The fortune at the bottom of the pyramid. Strategic Business, v. 26, p. 1-14, 2002.

PRITCHETT, L.; KENNY, C. Promoting Millennium Development Ideals: The Risks of Defining Development Down. WorkingPaper 338. Washington, DC: Center for Global Development, 2013.

SCHUMPETER, J. A. Capitalismo, socialismo e democracia.Rio de Janeiro: Editora Fundo de Cultura, 1961.

SOARES, S. S. D. Metodologias para estabelecer a linha de pobreza: objetivas, subjetivas, relativas, multidimensionais. Rio de Janeiro: IPEA, 2009.

TIDD, J.; BESSANT, J.; PAVITT, K. Gestão para inovação. 3. ed. Porto Alegre:Bookman, 2008.

VRAKKING, W. J. The innovative organization. Long Range Planning, v. 23, n. 2, p. 94-102, 1990. 